\title{
Research on the Mechanism of Quality Development Promoting Regional Economic Growth
}

\author{
Zhi XU ${ }^{1, a}$, Long-Sheng CHENG $^{1, b, *}$, Jing JIANG ${ }^{2, c}$ \\ ${ }^{1}$ School of economics and management, Nanjing University of Science and Technology, Nanjing, \\ 210094, China \\ ${ }^{2}$ Quality and Technology Supervision Bureau of Jiangsu Province, Nanjing, 210035, China

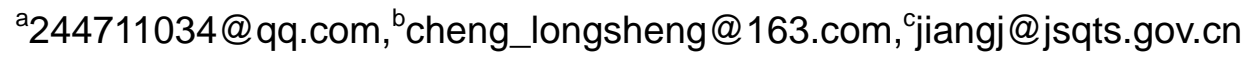 \\ ${ }^{*}$ Corresponding author: Long-Sheng CHENG
}

Keywords: Quality development, Regional economic growth, Index system, SEM.

\begin{abstract}
To some extent, quality development plays a critical part in changing the economic growth pattern and improving the stability and sustainability of economic growth, which could, as a result, make a difference on the quality and speed of regional economic growth. This work, sets up a index system of quality development and economic growth from multidimensional aspects, which make sure that the indexes are quantifiable, independent and reasonable. Based on the theory of Structure Equation Modeling(SEM), an initial model reflected the mechanism of quality development promoting regional economic growth is established. The paper explore the key factors, the hypothesis of the logical relationship between variables and the model fitting degree by solving and revising the model. Thus this paper puts forward the corresponding suggestions about quality management.
\end{abstract}

\section{Introduction}

With the challenges and changes brought by economic globalization, a great economic transformation is emphasized by the government, which can leads to the high quality of economic growth. At this stage, the improving rate of quality level is far behind the economic growth rate. The phenomenon that chasing the quantity and speed of economic growth but neglecting the quality and efficiency of economic growth still exists. So the work in this paper is of guidance to quality management.

The index system of quality development and economic growth were discussed by many researchers. For quality development, Some scholars researched on the important dimensions of quality management, like Flynn[1], Kumar[2]and so on. For economic growth, different dimensions of economy were discussed by many researchers[3,4].

SEM is a very important new statistical analysis method. SEM has some advantages which are different from those classical statistic methods, and it has been admitted by more academicians. By conducting the measurement model and structure equation model, the relations of variables latent or observed are calculated and verified through SEM. It has been applied into all kinds of science field as business management, project evaluation, society evaluation, safety in production and so on[5,6].

In this paper, based on the theory of SEM, five latent variables named quality investment from government, quality investment from firms, quality performance, quality of economic growth and speed of economic growth are established. The Criteria for Performance Excellence is brought into the design of the index system. Thus the initial model contains the measurement and structural model is established, then statistical estimates are used to validate the built model. The data analysis enables the acceptance or rejection of the hypothesis that has been stated on the basis of structural model. By the end, advice related on the quality management is proposed through the results.

\section{The Initial Model and Hypothesis}

Quality development is concept covering a wide range, such as technology, system, facilities, 
manpower and so on. In this paper, quality development is divided into two aspects, one is quality investment, the other is quality performance. For region economic growth, cause the economic transformation is necessary at this stage, both the quality and speed of economic growth are considered in this model. The initial model is shown as Fig.1.

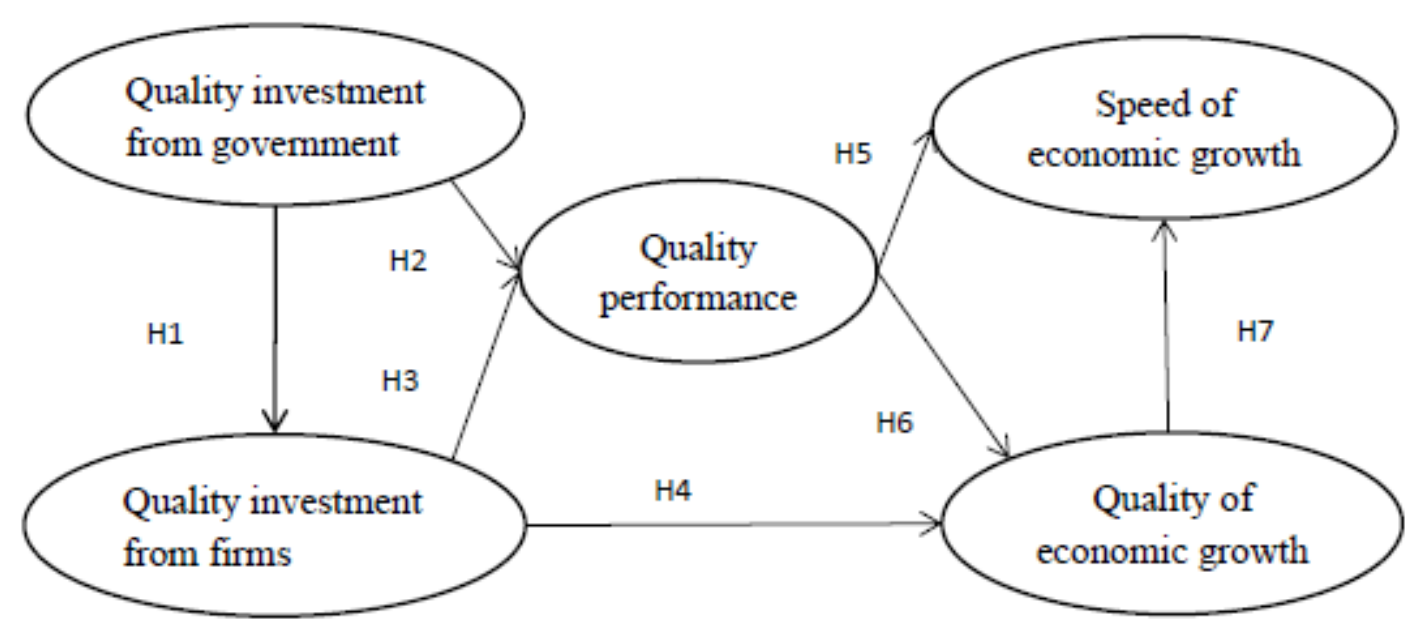

Fig.1 The initial model

There are five latent variables in the model. We can see that quality investment from government is the external variable, the other four variables are internal, in which the quality performance is the intermediate variable. This model explains the mechanism that how quality development make a difference on regional economic growth.

In this paper, seven hypothesis are proposed as follows:

H1:The quality investment from government has a significant positive impact on the quality investment from firms.

H2: The quality investment from government has a significant positive impact on the quality performance.

H3: The quality investment from firms has a significant positive impact on the quality performance.

H4: The quality investment from firms has a significant positive impact on the quality of economic growth.

H5: The quality performance has a significant negative impact on the speed of economic growth.

H6: The quality performance has a significant positive impact on the quality of economic growth.

H7: The quality of economic growth has a significant negative impact on the speed of economic growth.

\section{Design of the Index System and Data Resources}

\section{Design of the Index System}

To explain the latent variables, we designed the indexes for them. Based on the theory of big quality, Criteria of Performance Excellence, scientific outlook on development and so on, the index system are set up reasonably and rigorously. The final observed variables are presented as below.

There are 3 observed variables in the quality investment from government, which are $\mathrm{X}_{1}$ quality investment from government finance, $\mathrm{X}_{2}$ investment on the public platform for detecting and quality service, $\mathrm{X}_{3}$ investment on the upgrading of manufacturing industry.

There are 11 observed variables in the quality investment from firms, which are classified into six aspects by the Criteria of Performance Excellence. For the manpower part we choose $\mathrm{X}_{4}$ wage of quality controller, $\mathrm{X}_{5}$ training costs for quality; For the financing part, $\mathrm{X}_{6}$ certificating and maintaining costs for products and management system, $\mathrm{X}_{7}$ detecting costs for quality, $\mathrm{X}_{8}$ improving costs for quality, $\mathrm{X}_{9}$ the special funds for standardization, $\mathrm{X}_{10}$ costs for brand building 
and maintaining are selected; For the information and knowledge part, we choose the $\mathrm{X}_{11}$ building and maintaining costs for the information system; For the technical part, $\mathrm{X}_{12}$ investment on R\&D is selected; For the infrastructure part, we choose $\mathrm{X}_{13}$ the upgrading costs for infrastructure; For the partnerships, we choose $\mathrm{X}_{14}$ costs for managing suppliers.

There are 5 observed variables in the quality performance, which are classified into six aspects as products and service, customer and market, finance and benefit, resources, process efficiency, leadership and responsibility by the Criteria of Performance Excellence. The variables are $\mathrm{X}_{15}$ qualified rate of selected supervising, $\mathrm{X}_{16}$ market share of main products, $\mathrm{X}_{17}$ growth rate of firms' profit, $\mathrm{X}_{18}$ number of firms under the integration of regional industrialization and information, $\mathrm{X}_{19}$ number of firms confirmed by measurement system of national and provincial level, $\mathrm{X}_{20}$ number of firms confirmed by Government Quality Award(GQA) in turn.

Quality of economic growth has three multidimensional aspects, which are pattern of economic growth, structure of economic growth and benefit of economic growth. There are three developmental indicators to gauge the pattern of economic growth, and they are $\mathrm{X}_{21}$ overall labor productivity, $\mathrm{X}_{22}$ the energy consumption for ten thousand Yuan output value, $\mathrm{X}_{23}$ number of invention patents out of billion-yuan output. For the structure of economic growth, we choose $\mathrm{X}_{24}$ the proportion of the service industry added value in GDP, $\mathrm{X}_{25}$ the proportion of the high tech industry added value in GDP, $\mathrm{X}_{26}$ the proportion of producer services added value in GDP; For the benefit of economic growth, we choose $\mathrm{X}_{27}$ the proportion of Main business income from brand companies.

There are two observed variables in the speed of economic growth, and they are $\mathrm{X}_{28}$ regional GDP per capital, and $\mathrm{X}_{29}$ growth rate of public revenue.

\section{Data Resources}

Base on the issue named "Research on the contribution of quality development prompting regional economic growth", the investigation is organized by Jiangsu institute of quality and standardization. Related institutions and firms from Suzhou, Yangzhou and Suqian are asked to fill in the blanks in the questionnaire. The distribution of the samples in the three cities is established by GDP's proportion. Thus data are obtained.

\section{Solve and Revise the Model}

\section{Method for Analyzing}

In this paper, data are obtained from the questionnaire which is required to fill with the recorded data. In this situation, it is not qualified to do the validity analysis and reliability Analysis. Undoubtedly the index system is reasonable and rigorous cause it comes from much literature research, besides, theories of big quality, Criteria of Performance Excellence, scientific outlook on development are applied into the design of index system. Later in the revising process, the index which are of lower factor loading will be erased to simplify and fit the model.

Data are required to be multivariate normal distribution through the common method-ML(Maximum Likelihood), so we applied GLS(Generalized Least Squares) to solve the model. Some advantages of GLS make it a better choice for this research[7,8]. The first is that data is not required to be multivariate normal distribution, second is that GLS better fits the situation that samples are less than 500, third is that GLS is of more robustness. The software Amos21 is applied to do the calculation.

\section{Solving Results of the Initial Model}

Based on the initial model which reflected the mechanism of quality development promoting regional economic growth, we draw up the relations between latent variables and observed variables and import data through Amos 21. Then the original solving results are obtained. Table 1 shows the fitting index of the initial model. 
Table 1 fitting index of the initial model

\begin{tabular}{|l|l|l|l|l|l|l|l|l|}
\hline Fitting Index & $X^{2}$ & $d f$ & $X^{2} / d f$ & $G F I$ & $C F I$ & $I F I$ & $T L I$ & $R M S E A$ \\
\hline Value & 643.233 & 459 & 1.401 & 0.876 & 0.371 & 0.441 & 0.32 & 0.067 \\
\hline
\end{tabular}

We can see from table $1, \chi^{2} / d f<3$, the value of RMSEA is less than 0.08 , but the value of CFI, IFI, TLI are relatively low. To some extent, the model conforms to the evaluating standard, but still needs to be improved. In addition, we notice that pathway coefficient of hypothesis 4 isn't significantly different from 0 at the 0.05 level. Showing that this pathway cannot be verified and model needs to modified.

\section{Modifying of the Initial Model}

From the standardized factor loading, some factors of lower loading need to be erased to simply and optimize the model. We can see that factor loading of $X_{2}, X_{4}, X_{5}, X_{6}, X_{8}, X_{16}, X_{19}, X_{20}, X_{23}, X_{25}$, $\mathrm{X}_{26}, \mathrm{X}_{27}$ are all less than 0.4 , so they are removed from the model. Besides, pathway coefficient of hypothesis 4 which reflected the relation between investment from firms and quality of economic growth is not verified. For the reason that investment from firms always have a long-term and slight impact on quality of economic growth, which can be neglected, we remove this pathway and the final model is reached. The pathway coefficients of the final model is shown in Fig. 2.

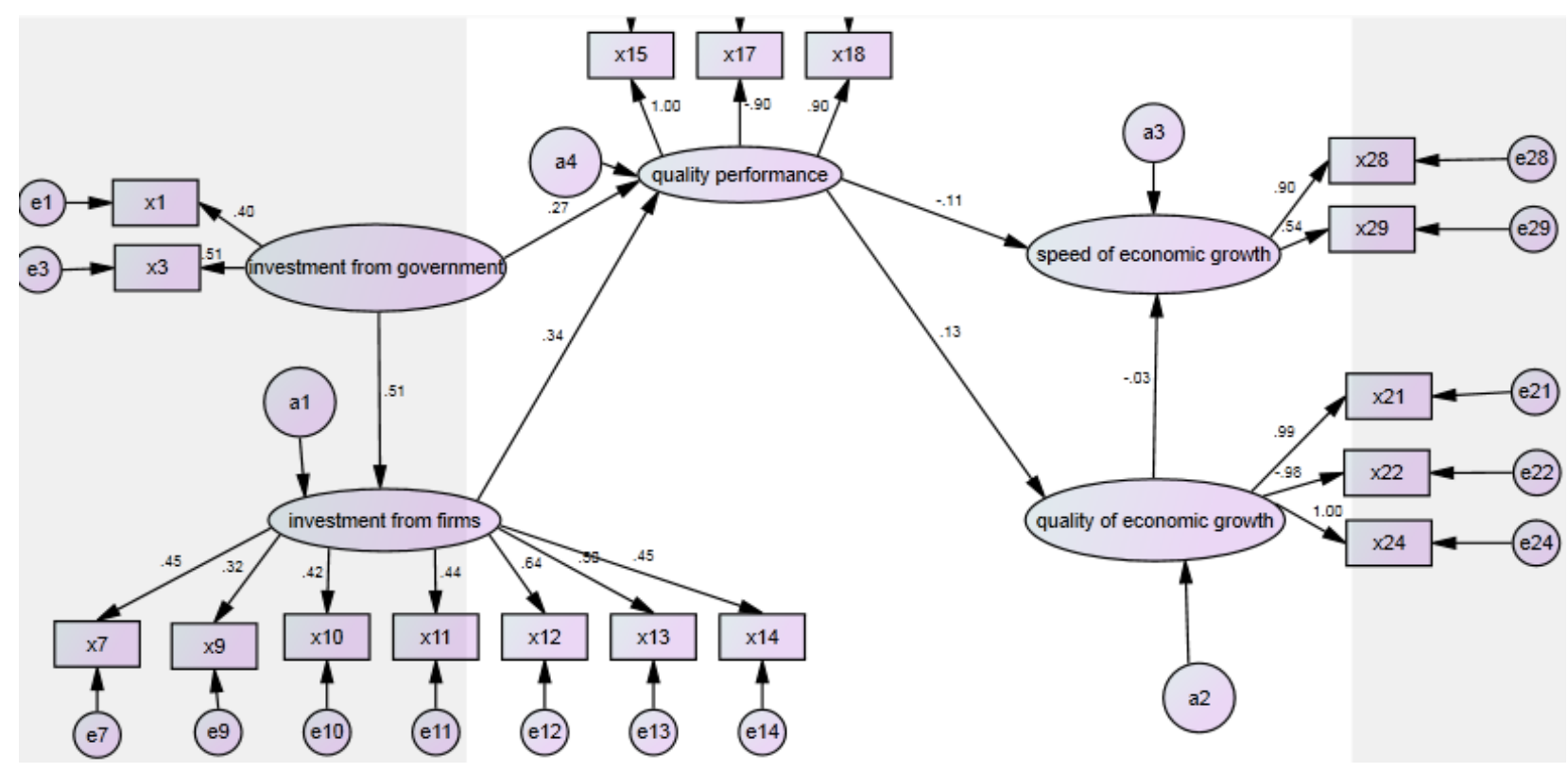

Fig.2 Pathway coefficients of the final model

The corresponding fitting index is shown in table 2.

Table 2 Fitting index of the final model

\begin{tabular}{|l|l|l|l|l|l|l|l|l|}
\hline Fitting index & $X^{2}$ & $d f$ & $X^{2} / d f$ & GFI & CFI & IFI & TLI & RMSEA \\
\hline Value & 150.48 & 114 & 1.32 & 0.89 & 0.942 & 0.943 & 0.931 & 0.035 \\
\hline
\end{tabular}

The fitting indexes of the final model are relatively better compared to them of the initial model. At this stage, the final model is established.

\section{Conclusions}

Through analyzing the final model, all the pathway coefficients are verified. Table 3 shows the effects between the latent variables, including total effects, direct effects and indirect effects. 
Table 3 Effects of the latent variables

\begin{tabular}{|c|c|c|c|c|c|c|}
\hline & & $\begin{array}{l}\text { Investment } \\
\text { from } \\
\text { government }\end{array}$ & $\begin{array}{l}\text { Investment } \\
\text { from } \\
\text { firms }\end{array}$ & $\begin{array}{l}\text { Quality } \\
\text { performance }\end{array}$ & $\begin{array}{l}\text { Quality of } \\
\text { economic } \\
\text { growth }\end{array}$ & $\begin{array}{l}\text { Speed of } \\
\text { economic } \\
\text { growth }\end{array}$ \\
\hline $\begin{array}{l}\text { Investment } \\
\text { from } \\
\text { firms }\end{array}$ & $\begin{array}{l}\text { Direct effects } \\
\text { Indirect } \\
\text { effects } \\
\text { Total effects }\end{array}$ & $\begin{array}{l}0.51 \\
0.51\end{array}$ & & & & \\
\hline $\begin{array}{l}\text { Quality } \\
\text { performance }\end{array}$ & $\begin{array}{l}\text { Direct effects } \\
\text { Indirect } \\
\text { effects } \\
\text { Total effects }\end{array}$ & $\begin{array}{l}0.266 \\
0.175 \\
\\
0.441\end{array}$ & $\begin{array}{l}0.344 \\
0.344\end{array}$ & & & \\
\hline $\begin{array}{l}\text { Quality of } \\
\text { economic } \\
\text { growth }\end{array}$ & $\begin{array}{l}\text { Direct effects } \\
\text { Indirect } \\
\text { effects } \\
\text { Total effects }\end{array}$ & $\begin{array}{l}0.059 \\
0.059\end{array}$ & $\begin{array}{l}0.046 \\
0.046\end{array}$ & $\begin{array}{l}0.133 \\
0.133\end{array}$ & & \\
\hline $\begin{array}{l}\text { Speed of } \\
\text { economic } \\
\text { growth }\end{array}$ & $\begin{array}{l}\text { Direct effects } \\
\text { Indirect } \\
\text { effects } \\
\text { Total effects }\end{array}$ & $\begin{array}{l}-0.048 \\
-0.048 \\
\end{array}$ & $\begin{array}{l}-0.038 \\
-0.038 \\
\end{array}$ & $\begin{array}{l}-0.106 \\
-0.004 \\
-0.11 \\
\end{array}$ & $\begin{array}{l}-0.026 \\
-0.026 \\
\end{array}$ & \\
\hline
\end{tabular}

From Table 3, total effect between quality investment from government and quality investment from firms is 0.51 , and the total effect between quality investment from government and quality performance is 0.441 , which means quality investment from government prompts the firms invest more on quality, thus makes a big difference on quality performance. Above all, government should invest more on improving quality.

The direct effect between quality investment from firms and quality performance is 0.344 , and the indirect effect between quality investment from firms and quality of economic growth is 0.046. This reveals that all the upgrading activities on quality help us witness the improvement of quality performance and transformation of economic growth pattern.

Besides, the total effect between speed of economic growth and quality investment from government, quality investment from firms, quality performance, quality of economic growth are respectively $-0.048,-0.038,-0.11$ and -0.026 . We can conclude that investment on quality may slow down the growing speed to some extent, but it complies to the tendency that breaking the "Only GDP theory".

Among the indexes belonged to quality investment from government, the index that investment on the upgrading of manufacturing industry is of greatest impact. This provides a guidance to government that government may invest more on smart workshop or smart equipment and so on to upgrade the manufacturing industry.

Among the indexes belonged to quality investment from firms, the index that investment on $R \& D$ and the upgrading costs for infrastructure matter most. This means that firms may attach importance to the both aspects to improve the quality level, along with the developing of research power and perfection of infrastructure.

\section{Summary}

In this paper, we combined theoretical analysis and empirical analysis to design the overall index system on quality development and economic growth, established the theory structural equation model for revealing the impacting mechanism. Results showed that the model is fitting well. In the end, the corresponding suggestion based on coefficients estimating and verifying were put forward for some guidance on quality management.

\section{References}

[1]Flynn B B, Schroeder R G, Sakakibara S, A framework for quality management research and an associated measurement instrument, Journal of Operations Management. 11(4)(1994) 339-366. 
[2]Ashok Kumar, Kathryn E.Stecke, Jaideep Mo twani, A Quality Index-Based Methodology for ImprovingCompetitiveness:Analytical Development and Empirical Validation, 2002.

[3]World Bank. Allocation of FY98 net income, Washington DC:World Bank, 1997, pp.97-175.

[4]Bo-Ke JIANG, Qing-Qing LIU. A Study on the Indicators for the Pattern of Economic Growth, Fudan Journal. 4(2010) 64-71(In Chinese).

[5]Vinodh S, Joy D, Structural equation modeling of sustainable manufacturing practices, Clean Technologies and Environmental Policy. 14(1)(2012) 79-84.

[6]Doloi H, Iyer K C, Sawhney A, Structural equation model for assessing impacts of contractor's performance on project success, International Journal of Project Management. 29(6)(2011) 687-695.

[7]Zi-Jing ZHOU. Pattern of SEM-proficient in LISREL, Taibei, 2006.(In Chinese).

[8]Hu L T, Bentler P M, Kano Y, Can test statistics in covariance structure analysis be trusted, Psychological Bulletin. 112(2)(1992) 351-62. 